\title{
Concepts and principles of the sustainable digital technologies use: process science and activity theory view
}

\author{
Alexander $S$. Geyda ${ }^{1,2, *}$, Lyudmila $N$. Fedorchenko ${ }^{1}$, Igor $V$. Lysenko ${ }^{1}$, Aleksandra $S$. \\ Svistunova $^{1}$, and Dmitry $S$. Khasanov ${ }^{1}$ \\ ${ }^{1}$ St Petersburg Federal Research Center of the Russian Academy of Sciences, 19818814 Line, 39, St. \\ Petersburg, Russia \\ ${ }^{2}$ The North-West Institute of management - branch of the Russian Presidential Academy of National \\ Economy and Public Administration, 197376 Pesochnaya Embankment, 4, St. Petersburg, Russia
}

\begin{abstract}
Using information technologies and implemented with their help information operations to implement sustainable development systems in the economy and society is considered. Based on the previously performed systematic literature review, the conclusions made about future research directions on using information technologies for sustainable development. A set of corresponding theoretical tools is proposed. This set should allow solving the problem based on mathematical models and methods. The concepts and principles of using information operations to study sustainably developed systems are proposed to solve the specified problem.
\end{abstract}

\section{Introduction}

The systematic literature review [1] on the problems of digitalization of the economy and society allowed us to conclude: one of the most important and promising areas of using modern (i.e., digital) information technologies is ensuring the sustainable development of the economy, society, and the state, strategic planning in the economy and society, creating a closed-cycle economy. This perspective is because information technologies allow us to justify, predict, and then organize and implement various types of changes in economic, social, and societal systems in general. As a result, by digital technologies, it becomes possible to implement a study of possible future effects of activities where it was previously impossible and, as a result, to make progress in solving the problems of sustainable development. It is possible to implement new, better forecasts with better accuracy for longer planning horizons with digital technologies. Digital technologies allow us to organize new ways of reusing and disposing of resources of different types. As a result, this may enable us to solve the problems of sustainable development of societal systems that were impossible to solve earlier. Digital technologies allow us to organize new ways of reusing and disposing of different types of resources. As a result, this may enable us to solve the problems of sustainable development of societal systems that were impossible to solve earlier. However - on the other hand, based on the conducted review, it was concluded that the existing

\footnotetext{
*Corresponding author: geida@iias.spb.su
} 
theoretical means of studying the use of digital technologies, especially mathematical models, and methods for solving such problems, are developed insufficiently. In particular, mathematical models and methods for solving sustainable development problems of various systems, as mathematical problems, are developed insufficiently well.

In this regard, within the developed theory of the use of information in systems functioning, it is possible to create theoretical means of studying digital technologies of sustainable development. According to the review results, these tools, and the means of the theory of the use of information in the functioning of systems should be based on the process science and the theory of activity. In addition, it is promising to use extensions of the graph theory, the alternative stochastic networks, the algebra of cyclograms, and the partially ordered sets. The article analyzes the main results of these theories in the application to the formal means of information technologies for sustainable development. It suggests concepts, principles, and basic schemas for using the information in the functioning of systems. Their further formalization should allow us to move on to the mathematical modeling of information technologies for the sustainable development of systems.

\section{The concept of the use of information operations for sustainable development}

The concept includes a set of interrelated concepts and principles of research of sustainable systems functioning regarding digital technology use. They are generated based on a systematic review [1] of conceptual and mathematical models, methods, and technologies for studying the digital transformation of economic and social systems.

The systematic review of the publications allowed us to draw the following conclusions, which would enable us to justify the direction of research on the use of information operations in the study of the functioning of sustainable developed systems:

First, it is necessary to eliminate the discrepancy between the need to consider the aspects of using information technologies for sustainable development and the limited available theoretical means.

Second, it is necessary to eliminate the discrepancy between the need to use predictive mathematical means for studying the results of activities in different types of systems - from the one hand. And from another hand, the lack of such mathematical means allowing studying activities, considering the predictive mathematical dependencies between the characteristics of the information technologies used, the results of activities obtained, and their compliance with the requirements.

Third, the closest to the required theoretical means for solving the problems of sustainable development regarding digital technology use indicated. According to the review results obtained, these are means, one way or another, based on the study of the role of information and information technologies in activities following the "activity paradigm" of the research. The keywords related to such a paradigm include Process Science, Complexity Science, Applied Activity Theories; Systematic-Structural Activity Theory; Activity Theory; Action Theory; Action Research, Digital Philosophy.

This conclusion is related to the need to link different types and aspects of information and activities based on the "process" and "activity" paradigms. First of all, information activities related to the acquisition and transformation of knowledge, training, social activities, and the psychology of information action — on the one hand, and — on the other hand, subject-transforming, energy-material, and instrumental actions. Theoretical means to link informational and other activities are necessary, in our opinion, to solve the problems noted earlier as unsolved. Examples of using the "activity approach" for different types of activities using information and information technologies are presented in[7,8]. 
The "activity approach" (or "activity paradigm") has a much greater generality because it is based on the description of the activity, including information aspects. However, at the time of writing this article, it does not contain theoretical means of predictive analytical evaluation of activities, their results, their compliance with requirements-depending on the characteristics of the information technologies used. When writing, its mathematical tools are mainly limited to project and program modeling tools and partly to project management tools. However, these tools do not describe the use of information technologies and the relationship between IT characteristics and the characteristics of the implemented activity. Thus, it should be noted that the theoretical tools of the "activity approach," on the one hand, are characterized by interdisciplinarity and breadth. Still, largely due to this, they are deprived of well-established mathematical means for solving problems. Thus, it is necessary to eliminate two different deficiencies caused by the current theoretical means for solving problems using information technologies for sustainable system actions.

\subsection{Concepts of information operations use for sustainable development systems research}

The concepts of using information operations for sustainable systems are proposed to form based on the process science and activity sciences (activity theory, action theory, action research). The concepts are proposed to explain and expand the suggested results with information, information operations, their relations with human activity, the environment, and sustainable development.

Following [2] we define process science as “...the interdisciplinary study of continuous change. By process, we mean a coherent series of changes that unfold over time and occur at multiple levels". Thus, by process science use regarding information actions, performed according to certain information technologies (IT) it is possible to explain value of IT, including but not limited - on the design stage.

Process science emphasizes the following key characteristics: (1) processes are in the focus, (2) we scientifically investigate processes (3) we do that through an interdisciplinary lens, and (4) we intend to influence and change processes to create needed impact.

In accordance with our earlier works [3-8], it is targeted changes that require information operations, possibly of different types. We define information [9] as a form - for example, a record on some "information carrier" - of the existence of ideas or thoughts (representations, concepts, judgments) in the material world (that is, outside of consciousness). Information is necessary for use to obtain the required results of human activity. Thus, we distinguish reflection, which is observed in the material world and without people, from information reflecting people's ideas. Informational operation (Information operation, operation with information) - an operation (an element of activity with specified goals, methods, and predictable implementation results) intended to obtain the required information (because of operating with information). The description of interrelated information operations is contained in information technology - a set of descriptions of possible information operations in different conditions and possible relations.

Sustainable development [10-12] (concerning digital technologies, process science, and activity sciences) is defined as follows. It is the ability to create and use information about the possible future results of the implementation of various types of activity (i.e., development, provision, and management) to meet the needs of the near future as well as the possible needs of future generations. The role of IT in such processes of activity is associated with the prediction, organization, regular monitoring, and change of activities in order for this activity to cause as a little negative and as many positive consequences as possible at the planning horizons that are marginal for research in the existing conditions. In this sense, this interpretation is close to the subject of strategic planning. However, it is aimed at greater 
detail of possible threats to the environment. This role of IT differs significantly from the traditional (and, nevertheless, still insufficiently studied) role. This traditional role consists in providing targeted changes in the processes of activity on limited planning horizons with the specified final goals of a limited number of stakeholders, i.e., as a rule, without considering the consequences for the environment and the development of the system on long-term planning horizons.

Along with the process science various action and activity theory approaches [13-23] to information operations research must be taken into consideration. This is necessary because of process science has not for now genuine concepts and methodologies of action research. Such concepts and methodologies, being adapted by using the information in system action theory, may allow to describe organizational [24, 25], social [26, 27], economic [28], psychological [29], cultural [30,31], cognitive, behavioral [32], environmental and sustainability [11, 33, 34], educational [30, 35-37] aspects of using information [38] for system action. Principles of the research of using information operations in s [39] system action suggested based on concepts suggested, as well as on process science and action theory results.

\subsection{Principles of the research of using information operations in system action}

The first principle is: effects of the use of information are changes inside or outside the mind. We should measure the results of such use according to characteristics of the change, their relationships with change and the extent to which changes comply with human demands. This principle corresponds to process science in that respect, measuring information operations results we shall measure changes of different kind and such measurement should be in the core of process science, too. However, when consider information operations levels of change shall be accounted for. Information operations must be used to design, to prepare any process. But change of the processes and higher level of changes made with information operations use too and thus - higher levels of changes shall be accounted for when quality of the information operation is measured.

The second principle is - we can measure quality of information use in a given system according to the characteristics of changes caused by information Im, which changes the relationship between action elements and action effects and their compliance with human demands.

The third principle is: the contour of possible changes due to information actions ends when changes in the material world occur. At that point, we can measure the results of using information.

Thus, after a series of changes in the environment and subsequent reactions of a sustainably developing system using information technologies, it is necessary to consider subsequent possible changes depending on certain alternative events in the environment and system. As a result, sequences of alternative changes or scenarios of possible changes are formed. According to the characteristics of possible sets of such scenarios and their compliance with the requirements, the functioning of steadily developing systems should be evaluated-depending on the conditions and characteristics of information operations (and the corresponding information technologies).

As a result, it becomes possible to assess the quality of a sustainably developing system analytically. That is - assessing using mathematical models of possible scenarios of environmental changes and subsequent reactions of a sustainably developing system based on evaluating the compliance measures of the functioning results of steadily developing systems with (changing) requirements. 


\section{Conclusion}

Based on the review of the current study results of the use of information operations and related technologies in the functioning of sustainably developed systems, the concept of using information operations in the study of sustainably developed systems is proposed based on the science of processes and theories of activity. The basic concepts and principles of using information operations to study the functioning of sustainably developed systems are substantiated. The obtained results allow us to construct mathematical models of sustainably developed systems' functioning regarding information technologies used in changing conditions.

\section{Acknowledgements}

The reported study was funded by RFBR, project number 20-08-00649, 19-08-00989 and by budget research work number 0073-2019-0003.

\section{References}

1. A.S. Geyda, T.N. Gurieva, V.N. Naumov. Conceptual and mathematical models, methods, and technologies for the study of the digital transformation of economic and social systems: a literature review and research agenda. Management consulting (2021), In press

2. J. vom Brocke, W. V. der Aalst, T. Grisold, W. Kremser, J. Mendling, B. Pentland., J. Recker. Process Science: The Interdisciplinary Study of Continuous Change (2021)

3. A. Geyda, Conference of Open Innovation FRUCT 28: FRUCT Oy, 9347589 (2021)

4. A. S. Geyda, Workshop on computer science and information technologies (2019)

5. A. S. Geyda, Proceedings of the 25TH conference of FRUCT association, 95 (2019)

6. A. Geyda, Recent Research in Control Engineering and Decision Making, 379 (Cham: Springer International Publishing, 2019)

7. A. Geyda, Future Internet, 11, 62 (2019)

8. A. Geyda, Information, 11(3), 164 (2020)

9. A. S. Geyda, Fundamentals of the theory of the potential of complex technical systems (Publishing House of the Russian Academy of Sciences, 2021)

1. D. J. Lang, A. Wiek, M. Bergmann, Sustainability Science, 7(1), 25 (2012)

10. I.-A. Hengst, P. Jarzabkowski, M. Hoegl, M. Muethel, Academy of Management Journal, 63(1), 246 (2020)

11. F. Popa, Futures, 65(4), 45 (2015)

12. J. Aranzadi, Toward a General Theory of Action, 9 (2018)

13. G. Goos, J. Hartmanis, J. van Leeuwen, M. Thielscher, Challenges for Action Theories (2000)

14. M. Thielscher, Action programming languages (2008)

15. M. Staron, Action Research in Software Engineering (2020)

16. N. V. Patel, Deferred Action: Theoretical Model of Process Architecture Design for Emergent Business Processes, 29 (2011)

17. R. P. Cooper, Topics in cognitive science, 13(1), 63 (2021)

18. P. J. Ågerfalk, European Journal of Information Systems, 13(1), 80 (2004) 
19. X. Ma, Data-Information-Knowledge-Action Model, 1 (2018)

20. V.E. van Reijswoud, H.B.F. Mulder, J.L.G. Dietz, Information Systems Journal, 9(2), 117 (1999)

21. F. Piovesan, Action Research, 3(2), 147675032091916 (2020)

22. B. Dick, Action Research, 7(1), 5 (2009)

23. E. Turban, Information technology for management, 460 (2015)

24. S. Karanasios, Information Technology \& People, 31(1), 134 (2018)

25. K. Umapathy, Information Systems Theory, 59 (2012)

26. R. Miettinen, Journal for the Theory of Social Behaviour, 42(3), 345 (2012)

27. L. V. Mises, Human activity: a treatise on economic theory, 878 (2019)

28. G. Z. Bedny, Work activity studies within the framework of ergonomics, psychology, and economics (2019)

29. A. Sannino, Cultural-Historical Psychology, 14(3), 43 (2018)

30. M. Cole, B. Ferholt, A. Jornet, Mind, Culture, and Activity, 26(4), 283 (2019)

31. I. Ajzen, Psychology \& health, 26(9), 1113 (2011)

32. W. C. Clark, Linking knowledge with action for sustainable development, 122 (2006)

33. J. W. Cook, Sustainability, Human Well-Being, and the Future of Education, 425 (2019)

34. T. Aagaard, Digital agency in higher education (2020)

35. A. Emejulu, Critical Studies in Education, 60(1), 131 (2019)

36. S. Pal, Q. C. Ton, R. S. S. Nehru, Digital education pedagogy (2021)

37. S. Karanasios, Information Systems Journal, 28(3), 439 (2018)

38. C. J. Martin, Ecological Economics, 121, 149 (2016) 